MATEC Web of Conferences 25, 04005 (2015)

DOI: $10.1051 /$ matecconf/ 20152504005

(c) Owned by the authors, published by EDP Sciences, 2015

\title{
Foam Concrete Performance Study Based on Experimental Analysis
}

\author{
Chuan Yu \\ Capital Construction Division, Shandong Women's University, Jinan, Shandong, China
}

\begin{abstract}
In this paper, it studies the effect of the water-cement ratio, fly ash, PP fiber and high-performance expansion agent on the mechanical property and contractility of the foam concrete through experiments. The results of the experiment show that in the middle-late stages of hydration, the foam concrete shows the characteristic of contraction; when the water-cement ratio is between 0.3 to 0.5 , the greater the ratio is, the smaller the contraction of foam concrete will be; when the water-cement ratio is greater than 0.5 or less than 0.2 , the contraction amount of $28 \mathrm{~d}$ decreases. Fibers in random distribution may slightly reduce the shrinkage of foam concrete; while a certain content of expander can effectively compensate for the deformation shrinkage of foam concrete, and even realize no shrinkage in the early stage of hydration.
\end{abstract}

Keywords: foam concrete; water-cement ratio; contraction; expansion; compressive strength; crack control

\section{INTRODUCTION}

The foam concrete has excellent properties of light-weight, multi-aperture, fireproofing, heat insulation and sound insulation as well as shock absorption. It can also consume large amounts of industrial wastes in the production process, and it is consistent with the trend of China's current reform of wall materials and building energy efficiency policies, which has been conducted in small scale in the majority of our country. In addition, the fresh paste of foam concrete can not only realize the situ casting, which is widely applied on the structural material of building enclosure, but also in the field of foundation compensation of roadway support landscape decoration. Currently, the basic construction in China is in the ascendant, and there is a huge demand for foam concrete, what's more, the foam concrete has attracted more and more attention of the engineering sector for its safety and durability. However, during the preparation, construction and service stages of foam concrete materials, the phenomenon of noticeable shrinkage and crack are quite common, as the stability and crack control of foam concrete can affect the safety and durability of the project, even the usage effect and the whole project life. Therefore, the volume stability control of foam concrete has become one of the main directions regarding the foam concrete research. Meanwhile, in order to improve the quality of construction as soon as possible and promote the use of foam concrete materials, research on the crack control technology of foam concrete is also quite necessary.

The properties of foamed concrete have been investigated by many experts and scholars. Leilei Zhang and Wuxiang Wang studied the research progress and the application situation of foam concrete and proposed the problems and solutions about it ${ }^{[1]}$. Yonghao, et al. studied the influence of fly ash and foam amount on dry bulk density and compressive strength of cement-fly ash concrete, and analyzed the pore structure of foam concrete by means of reading microscope and image analyzing software. They focused on the relationships between the compressive strength and the pore structure on foam concrete and the relationship about mathematical formula between the compressive strength and the pore structural parameter on foam concrete ${ }^{[2]}$. Bin Cheng and Jie Liu investigated the influence of the micro silicon powder and polypropylene fiber on compressive strength and the splitting tensile strength and contraction rate of foam concrete. The apparent density of foam concrete was in the range of $800-1500 \mathrm{~kg} / \mathrm{m}^{3}$. The result showed that using mixing micro silicon powder and polypropylene fiber technology could fabricate the high strength foam concrete and its apparent density could reach the range of $800-1500 \mathrm{~kg} / \mathrm{m}^{3}$ and its compressive strength could reach the range of 10-50 MPa. That means the micro silicon powder and the polypropylene fiber could significantly increase the compressive strength of foam concrete ${ }^{[3]}$. Shun-E Zhou prepared a series of foam concrete, tested their compressive mechanic property, studied the characteristics of compressive stress-strain curves and simultaneously simulated the compressive process by using Gibson-Ashby model. The result showed that the compressing process included four stages: the platform stage, the dense stage, the yield stage and the decay stage. The compressive mechanic performances were affected by the factors of materials and appearance density, as well as the shape and distribution of pore ${ }^{[4]}$.E.K. Kunhanandan Nambiar researched the influence of various filling materials. The result indicated that the water retention of foam concrete with fixed density was decided by filler types, the fluidity of foam concrete mainly depends on the foam volume and the strength of foam concrete can be improved by reducing the particle size ${ }^{[5]}$. E.P. 


\section{MATEC Web of Conferences}

Kearsleya, et al. studied the influence of filling large number of fly ash on compressive strength. The result indicated that the strength of foamed concrete would not decrease when the $67 \%$ cement was replaced by fly ash. Meanwhile, they put forward a strength formula of foam concrete with density grade which is in the range of $1000 \mathrm{~kg} / \mathrm{m}^{3}-1500 \mathrm{~kg} / \mathrm{m}^{3}$ based on the water-ash ratio and the water-glue ratio and established the relationship model between ash replaced ratios ${ }^{[6]}$.

This paper research the influence of water-ash ratio, fly ash, PP fiber and high property sweller on the strength and contraction property based on previous studies, the regional scope of the Shandong Province, the regional scope of the original material of various brands, the premise, and the combination of the basic model features.

Table 1. Main materials used in the experiment

\begin{tabular}{|l|l|l|}
\hline $\begin{array}{l}\text { Name of } \\
\text { materials }\end{array}$ & Brand & Model \\
\hline Cement & Shanshui & 42.5R cement \\
\hline Fly ash & Binhui & I grade of fly ash \\
\hline PP fiber & Haojian & $\begin{array}{l}\text { Produced by polypropylene } \\
\text { and a variety of organic and } \\
\text { inorganic materials with } \\
\text { special composite technology }\end{array}$ \\
\hline $\begin{array}{l}\text { Foaming } \\
\text { agent }\end{array}$ & Guanyue & $\begin{array}{l}\text { HTD-1 type of composite } \\
\text { foaming agent }\end{array}$ \\
\hline $\begin{array}{l}\text { Water } \\
\text { reducer }\end{array}$ & Qineng & $\begin{array}{l}\text { PC455 polycarboxylate } \\
\text { superplasticizer }\end{array}$ \\
\hline $\begin{array}{l}\text { Expanding } \\
\text { agent }\end{array}$ & HCSA & $\begin{array}{l}\text { The main components are } \\
\text { C4A3S, CaO, CaSO4 }\end{array}$ \\
\hline
\end{tabular}

Table 2. Main equipment for materials

\begin{tabular}{|l|l|}
\hline Equipment & Photo \\
\hline $\begin{array}{l}\text { BC-300 type of digital } \\
\text { readout comparator }\end{array}$
\end{tabular}

\section{TEST}

\subsection{Raw materials and test equipment}

The materials and machinery equipment selected in this study are in line with the relevantly national standards or specifications, the detailed selected materials and machines are respectively shown in Table 1 and Table 2.

\subsection{Test method}

The high-pressure foaming machine is used to make the foaming agent into small bubbles. After the bubbles are mixed with well-stirred slurry according to a certain proportion, it will be injected into a mold which is $40 \mathrm{~mm} * 40 \mathrm{~mm} * 160 \mathrm{~mm}$ and cured for 24 hours. Then we conduct the form removal, and the curing should be conducted according to specified standard.

The foam concrete strength shall be tested in reference to GB / T17671-1999 "Cement Mortar Strength Test Method", the foam concrete shrinkage shall be tested in reference to JC / T603-2004 "Cement Mortar Shrinkage Test Method".

\section{RESULTS AND DISCUSSION}

\subsection{Effects of water-cement ratio on foam concrete performance}

Effect of water-cement ratio on the shrinkage and compressive strength of foam concrete are respectively shown in Figure 1 and Figure 2.

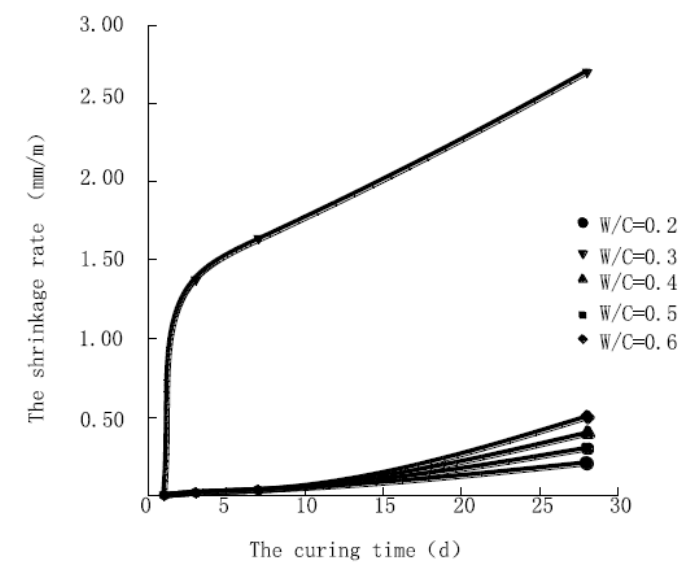

Figure 1. Effects of water-cement ratio to foam concrete shrinkage

As can be seen from Figure 1, the test specimens of foam concrete are in varying degrees of contraction. With the ongoing process of cementing materials hydration, the shrinkage value is increasing. It is mainly because during the hydration process and after the 


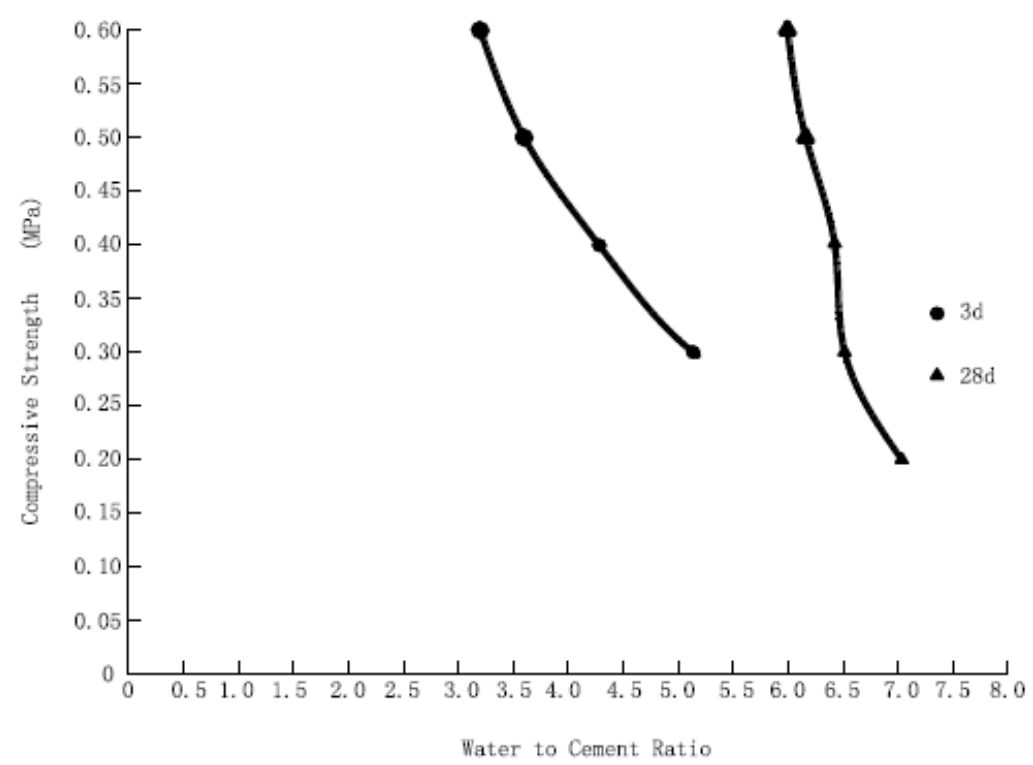

Figure 2. Effects of water-cement ratio to foam concrete compressive strength

hydration of solid particles, the volume is increasing and the particles are in intimate contact. The strength of the foam concrete frame is also increasing, but its liquid volume continues to decline. However, the total volume of solid and liquid decreases after hydration, while the gas volume increases. When the process takes place in the plastic stage with low strength of foam concrete slurry, the volume decreases at the macro performance. When the water-cement ratio is from 0.3 to 0.5 , the shrinkage value of foam concrete increases along with the water-cement ratio getting smaller, because in the cage structure of foam concrete, the hydration of cementing materials forms a large number of gel capillary; the smaller the water-cement ratio is, the less the free water content in the system can be. The hydration of cementing materials might reduce the relative humidity inside, and leading to dehydration or level drops within the capillary. The lower the humidity is, the larger the capillary force is. When the tensile strength of gelling system skeleton is less than the capillary tension, the self-contraction occurs, and the smaller the water-cement ratio is, the greater the contraction is. According to the theory of cement hydration, when the water-cement ratio is greater than 0.5 , the cement particles can be fully hydrated, its self-drying function and self-contraction are negligibly compared with the air shrinkage, therefore, the shrinkage value is very small; and when the water-cement ratio is less than 0.25 , the cement slurry exhibits a dry state. The solid-liquid volume ratio increases, the volume of cement particles after the hydration can gradually offset the reduced volume, and even reduce the amount of shrinkage instead.

As can be seen from Figure 2, with the decrease of water-cement ratio, the compressive strength of concrete foam increases; the smaller the water-cement ratio is, the greater the compressive strength is. The foam concrete is a kind of slurry that consists of solid phase, liquid phase and gas phase. The smaller the water-cement ratio is, the denser the gel skeleton structure of particles packing is, so the strength of the cell wall will substantially increase. On the whole, the strength of the foam concrete increases.

\subsection{Effects of absolute dry performance density on foam concrete performance}

Prepare foam concrete with the absolute dry performance density which is in the range of $400-800 \mathrm{~kg} /$ $\mathrm{m}^{3}$. Research the effect of absolute dry performance density on the contraction and compressive strength of foam concrete. The results are respectively shown in Figure 3 and Figure 4.

As can be seen from Figure 3, the absolute dry apparent density and contraction have a certain relationship. With the increase of absolute dry apparent density, the contraction decreases. It can be seen from the contraction curve that the volume change of foam concrete in early stage is not obvious, because during the hydration of cementing materials, the gradually reduced water has caused the reduction of its own volume. However, due to the added amount of ettringite in the material, the volume of materials has expanded in a certain degree, so the volume of concrete does not change significantly. As the ongoing hydration process at a later stage, the solid-liquid total volume decreases. The pores generate a negative pressure, resulting in an overall contraction. The contraction 


\section{MATEC Web of Conferences}

value decreases along with the increase of absolute dry apparent density, and the contraction speed is on a decline curve, because during the hydration process after the hydration of solid particles, the volume is increasing and the particles are in intimate contact The strength of the foam concrete frame is also increasing, but its liquid volume continues to decline. However, the total volume of solid and liquid decreases after the hydration, while the gas volume increases. When the process takes place in the plastic stage with low strength of foam concrete slurry, the volume decreases at the macro performance. The strength of foam concrete with great absolute dry apparent density is greater than the foam concrete with less absolute dry apparent density, whose ability to resist the shrinkage increases. The greater the absolute dry apparent density is, the smaller the contraction is.

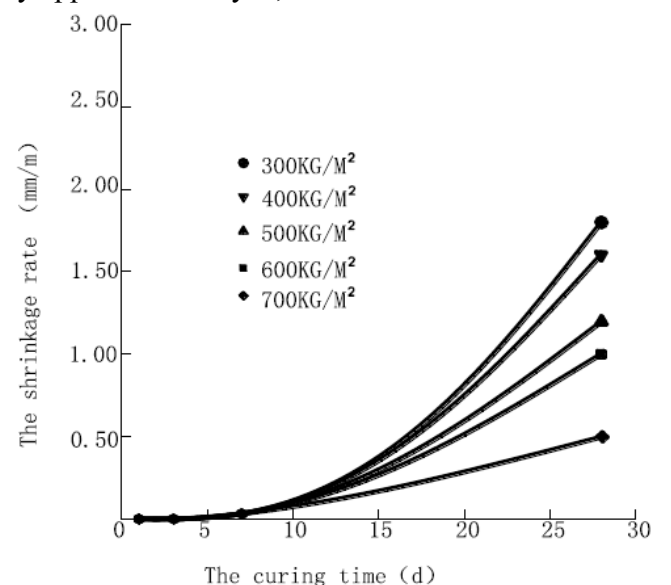

Figure 3. Effects of absolute dry performance density on concrete contraction

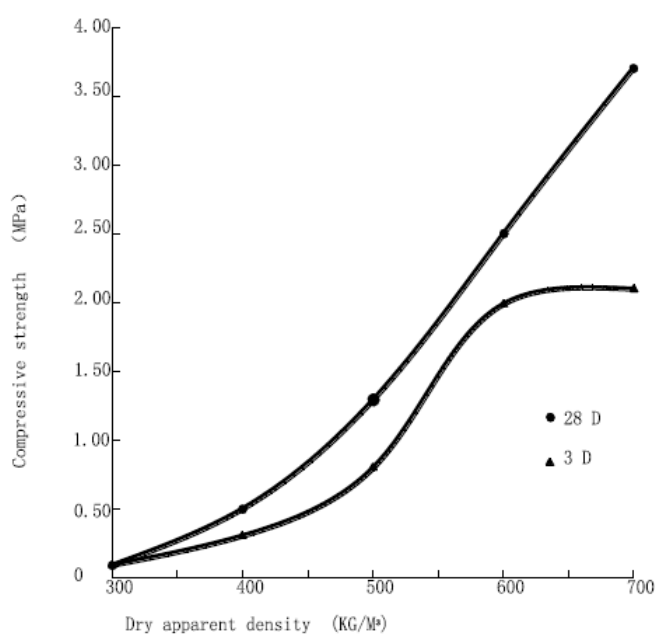

Figure 4. Effects of absolute dry performance density on concrete compressive strength
As can be seen from Figure 4, the strength of foam concrete with great absolute dry apparent density is greater than the foam concrete with less absolute dry apparent density. With the increase of the absolute dry apparent density, the compressive strength also keeps increasing. The greater the absolute dry apparent density is, the greater the total volume of hole wall materials that form foam concrete in the same volume space is. Under the same hydration condition, the greater the total number and volume of hole walls are, the higher the foam concrete strength is.

\subsection{Effects of fiber on foam concrete performance}

Mix $0.1 \%$ of PP fibers in the foam concrete, and prepare different foam concretes with the absolute dry apparent density between $400-800 \mathrm{~kg} / \mathrm{m}$, then study the impact of mixed fibers on the contraction and compressive strength of foam concrete that with different absolute dry apparent densities. Test results are respectively shown in Figure 5 and Figure 6.

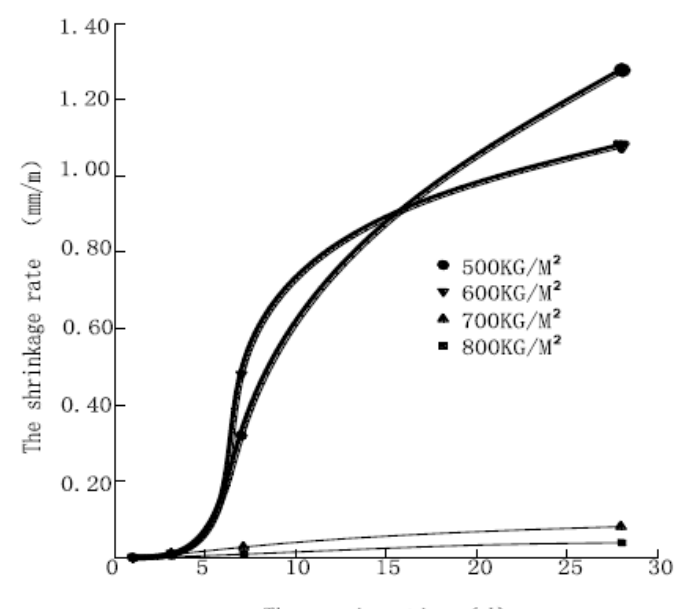

The curing time (d)

Figure 5. Contraction of foam concrete with different absolute dry apparent densities after the fiber mixture

It can be seen through the comparison between Figure 5 and Figure 3 that the added PP fiber plays a limited role on foam concrete contraction. PP fibers are the supporting system in a macro uniform random distribution of foam concrete sclerotium, which can delay or prevent the occurrence and development of early plastic shrinkage during the hardening process of foam concrete. At the same time, the cracks produced by the contraction inside the foam concrete are interdicted by the fibers in the development process of cracks, which can consume some shrinkage stress while the fiber can also reduce the tip stress concentration so as to prevent crack extension and expansion. In addition, by comparing Figure 6 and Figure 4, it can be seen that the introduction of PP fibers has improved the compressive strength of foam concrete, but it doesn't change the variation law of the curve. 


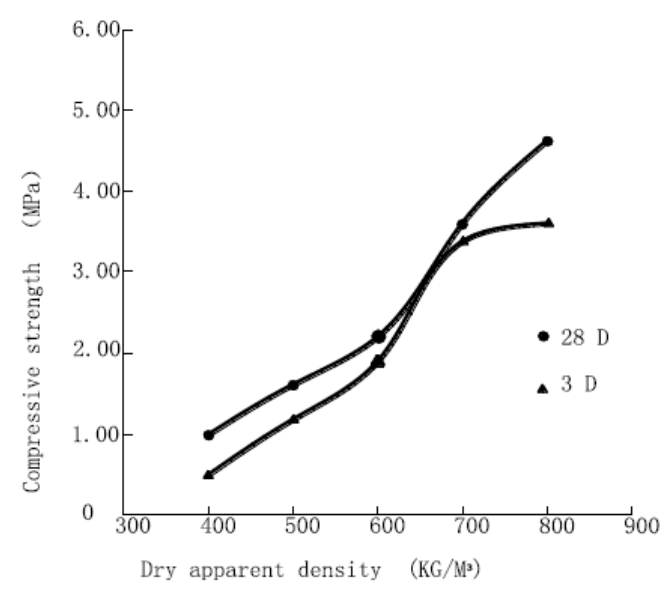

Figure 6. Compressive strength of foam concrete with different absolute dry apparent densities after the fiber mixture

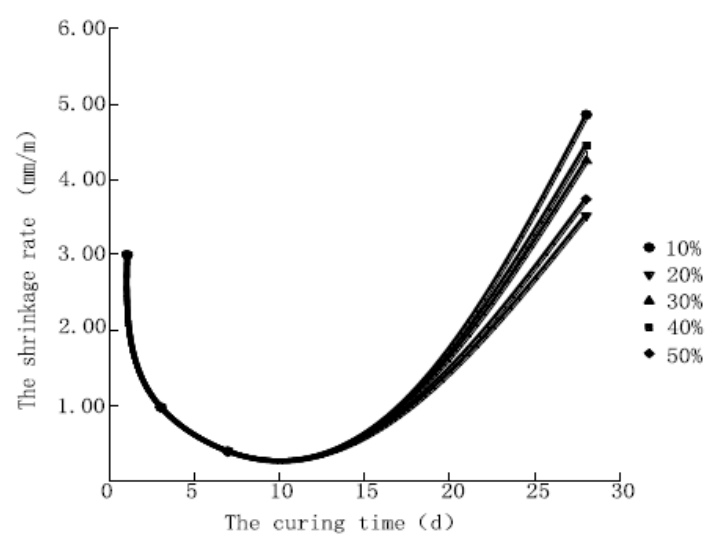

Figure 7. Effects of fly ash on contraction of concrete

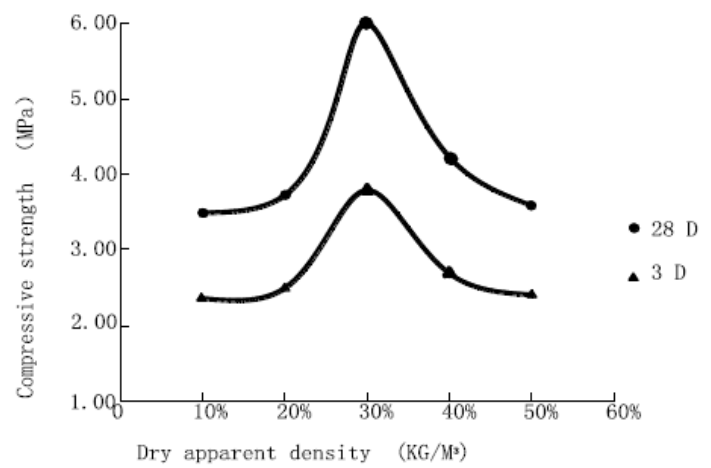

Figure 8. Effects of fly ash on compressive strength of concrete
3.4 Effects of fly ash on the performance of foam concrete

In ordinary concrete, the introduction of appropriate fly ash can reduce the unit volume heat of hydration system. It also can effectively reduce the internal temperature of concrete to improve the shrinkage properties of concrete. We studied different foam impact results of Volume Fly Ash Concrete Crack Control that are respectively shown in Figure 7 and Figure 8 .

As can be seen from Figure 7, after adding fly ash in the foam concrete, the volume of concrete at early age shows a slight increase. But it contracts at later stage, and the contraction value is not very different from Figure 1 of no added concrete.

As can be seen from Figure 8, with the added amount of fly ash, the compressive strength of foam concrete firstly increases decreases. When the amount of fly ash is $30 \%$, the $28 \mathrm{~d}$ compressive strength of foam concrete comes to a maximum (6.0MPa). Then the compressive strength gradually reduces, which is not very different from the characteristics of ordinary concrete, mainly because the fly ash is with both good pozzolanic activity and microaggregate effect. This kind of compressive strength on the hole wall of early microaggregate is much larger than the strength of pure gel. Meanwhile, as the ongoing hydration, the fly ash particles react with the calcium hydroxide - the product of cement hydration, which can produce calcium silicate hydrate with gelling properties and make hole wall more compact and with higher intensity. Therefore, the appropriate amount of fly ash can improve the strength of the foam concrete. When the fly ash amount is more than $30 \%$, the insufficient alkali content in the slurry and inadequate hydration of fly ash might result in lower strength. The larger the amount was, the more the strength reduced.

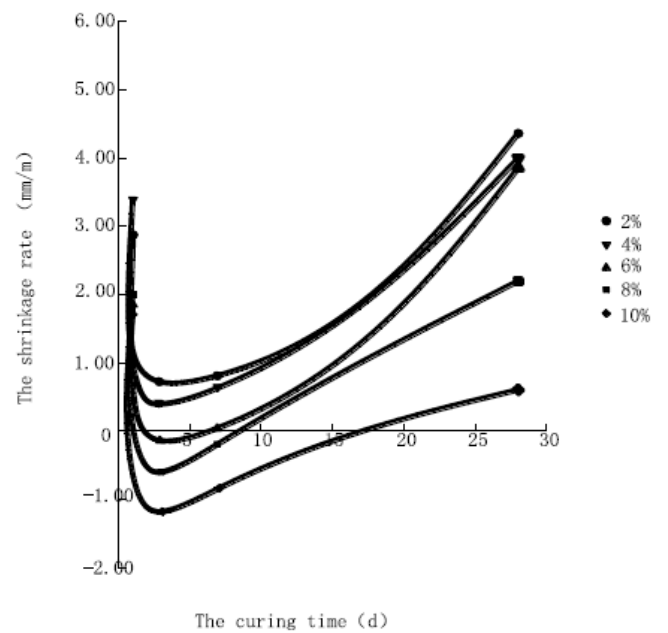

Figure 9. Effects of expanding agent on concrete shrinkage 


\section{MATEC Web of Conferences}

3.5 Effects of expanding agent on the performance of foam concrete

The shrinkage cracks of foam concrete are mainly caused by the volume change of foam concrete, while the volume change is primarily due to the result of chemical and physical effects. In order to reduce and eliminate foam concrete cracks, it is necessary to keep the volume stability of foam concrete. And the chemical expansion compensation is a more feasible way to achieve stability in the volume of foam concrete. This experiment studies the impact of the different contents of expanding agent on the foam concrete performance, and results are respectively shown in Figure 9 and Figure 10.

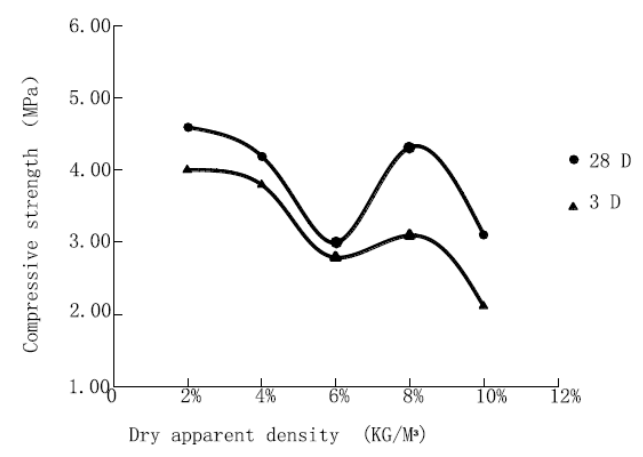

Figure 10. Effects of expanding agent on concrete compressive strength

As can be seen from Figure 9, when the expansive agent is more than $6 \%$, the performance of foam concrete shows little expansion in the early stage. With the increase of expansive agent, the early volume of foam concrete is also expanding. The reason is that the main component of HCSA expanding agent is the calcium sulphoaluminate, and its hydration product is ettringite. The volume expansion multiple of sulphoaluminate particles is 9.3 , which can effectively eliminate the chemical and physical contraction of foam concrete produced by the hydration of cement particles. In the absence of constraint, the overall performance in the later stage is contraction.

Figure 10 shows that after the incorporation of expansive agent to the foam concrete and with the increasing amount of expansive agent, the compressive strength has reduced. With comprehensive consideration, when the expansive agent is $8 \%$, the performance of foam concrete is micro-expanded in the early stage, and at the same time, the compressive strength is slightly declined to achieve better results.

The experiment of adding expansive agent to improve the performance of foam concrete shows that if both the expansive agent and constraint are introduced at the same time, the expansion generated at the early stage can be stored through constraint carrier, and it can be used to offset the contraction energy generated at the later stage of hydration, so as to solve the foam concrete shrinkage cracks problem, and other related work will be gradually carried out in subsequent studies.

\section{CONCLUSION}

It can be found out through experiment that the lower the absolute dry apparent density of foam concrete is, the lower the intensity is, but the greater the shrinkage. By adjusting the water-cement ratio, the foam concrete shrinkage can be reduced to a certain extent. When the water-cement ratio is greater than 0.5 , the cement particles can achieve complete hydration. Shrinkage becomes very small, but the strength decreases with the increasing water-cement ratio. It is helpful to improve the cracking problem by adding more fibers. With comprehensive consideration and by adding $8 \%$ of efficient expansive agent, the generated self-stress can effectively reduce the physical and chemical contractions that are generated by the foam concrete hydration in the early stage, and the contraction amount will also be reduced in later stage.

\section{ACKNOWLEDGEMENT}

This study is jointly supported by "Shandong Corporate Training and Employee Education Key Topics" (2014-219) and "2014 Shandong Provincial of Housing and Urban Construction of Science and Technology Program" (the first batch) (RK024).

\section{REFERENCES}

[1] Leilei Zhang \& Wuxiang Wang. 2010. Research progress of foamed concrete and application. Building Block and Block Building, (1): 38-42. China.

[2] Yonghao Fang, Rui Wang, Erbo Pang \& Zhou Yue. 2010. Cement - fly ash foam concrete compressive strength and pore structure of relationship. Portland Journal. 04: 621-626. China.

[3] Bing Chen \& Jie Liu. 2010. Experimental study on the performance of fiber reinforced foam concrete. Journal of building materials, 03: 286-290+340. China.

[4] Shun-e Zhou, Lu Zhongyuan, Lago \& San Xia Li. 2010 Foam concrete compression characteristics and compressive strength model. Wuhan University Journal, 11:9-13. China.

[5] Yang Fengyuan. 2012. The influence factor of foam concrete properties. Southwest University of Science and Technology, China.

[6] Kunhanandan Nambiar E K \& Ramamurthy K. 2006. Models relating mixture composition to the density and strength of foam concrete using response surface methodology. Cement and Concrete Composites, 28:752-760.

[7] Paul J Tikalskya \& James Pospisil. 2004. A method for assessment of the freeze -thaw resistance of preformed foam cellular concrete. Cement and Concrete Research, 34:889-893. 